\title{
Internal processes in decision- making (mental, emotional, cultural, ethical and spiritual) of Afghan business leaders
}

\author{
Mujeeb ur Rahman Ibneatheer, Pierre Rostan and Alexandra Rostan \\ Department of Business, American University of Afghanistan, Kabul, Afghanistan
}

\begin{abstract}
Purpose - The purpose of this paper is to understand, which internal processes (mental, emotional, cultural, ethical and spiritual) Afghan business leaders use when making managerial decisions.

Design/methodology/approach - Primary data were collected through 1-h face-to-face interviews with Afghan business leaders. Interviews were conducted through open-ended questions in a semi-structured format. This method was considered most appropriate to acquire an understanding of senior executives' interpretation and usage of decision-making processes. The method of analyzing data was thematic analysis where the researchers identified common themes, topics, ideas and patterns of meaning that come up repetitively. The objective of the analysis was to determine the most frequent decision-making processes by business leaders and the reasons for using these processes.

Findings - Although the usage of internal processes in decision-making are not homogeneous among Afghan business leaders, some of the processes are used more frequently than others such as mental, cultural and ethical processes. During the mental process of decision-making, the majority of leaders use intuitional decision-making, the minority using logic. Regarding the cultural dimension, the majority of leaders stated that they have an open, friendly, caring organization for each employee and horizontal culture in their organization. The minority indicated that they have a friendly culture but they also considered the processes and hierarchy in their organization. Considering the ethical process of decision-making, leaders stated that their priorities are more ethical than getting extra profit. They believe that profit will be generated while considering ethical values. As a leader noted: when you consider ethics and fulfill your obligations, the profit automatically generates. Most leaders use the internal process of emotion in their decision-making, but the usage has not been frequent. The emotional process of decision-making is more involved when the human factor is involved. For instance, one of the participants stated "I did not fire an employee that I had to because he was a needy and poor person." About the spiritual process of decision-making, although all leaders agreed that they have used spirituality in decision-making, its usage varies. About one-third of the leaders mostly rely on spirituality or on religious teachings during the decision-making process, one-third somehow rely on spirituality or religion, about $50 \%$ of the time and one-third rely on spirituality between $25 \%$ to $30 \%$ of the time.
\end{abstract}

Originality/value - This study is pilot research as no previous research was carried out on this topic, therefore, it provides a basis of literature on the usage of internal processes on decision-making in Afghanistan. The findings may differ in other economic and national contexts.

Keywords Leadership, Management, Decision-making, Internal processes

Paper type Research paper

(C) Mujeeb ur Rahman Ibneatheer, Pierre Rostan and Alexandra Rostan. Published in PSU Research Review. Published by Emerald Publishing Limited. This article is published under the Creative Commons Attribution (CC BY 4.0) licence. Anyone may reproduce, distribute, translate and create derivative works of this article (for both commercial and non-commercial purposes), subject to full attribution to the original publication and authors. The full terms of this licence maybe seen at http:// creativecommons.org/licences/by/4.0/legalcode

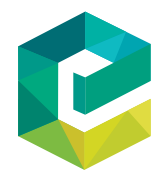

PSU Research Review Emerald Publishing Limited Emerald Publishing Limited
$2399-1747$ DOI 10.1108/PRR-10-2020-0037 


\section{Introduction}

Great leaders are great decision-makers (Case, 2010). Great leaders understand how to make decisions that positively impact their employees, their customers, their companies and finally themselves. One major quality of a great leader is decisiveness. Decisions should be clear, certain and somewhere quickly made to communicate the outcome to others in a timely manner. The objective of this study is to explore the most frequent factors (mental, emotional, cultural, ethical and spiritual), which influence the decision-making processes and to better understand the psychological process of decision-making among business leaders in Afghanistan. The research question is to identify, which ones, among the five precited factors, Afghan business leaders commonly select to make decisions in their daily work activities. The motivation of this research is to enhance leadership practices and decision-making among Afghan business executives and to provide new insights and guidelines to new entrepreneurs regarding decision-making based on the experience of their peers. The literature is reviewed in Section 2. The methodology is explained in Section 3. Section 4 presents the results. Section 5 presents the conclusion.

\section{Literature review}

The purpose of this exploratory study is to understand the utilization of the internal processes of decision-making among business leaders in Afghanistan. The literature review first focuses on the concept of decision-making, analyzes the link between leadership and decision-making and then looks separately at the five dimensions of decision-making, namely, mental, emotional, cultural, ethical and spiritual.

\subsection{Decision-making}

A decision is defined as a choice between several different options. The "decision-maker" makes such a choice. The choice can be made directly, but commonly the decision-maker is involved in a process that includes "identification, analysis, evaluation, selection and planning” (Selart, 2010, p. 65). Traditionally, leadership and decision-making are considered as two fundamentally distinct phenomena (Selart, 2010) while it is argued that problemsolving is a step toward decision-making (Kepner, 1997). Decision-making is an integral part of the process of management (Simon, 1960, p. 1) and "it comprises three principal phases, namely, finding occasions for making a decision; finding possible courses of action; and choosing among courses of action." Ofstad (Harrison, 1996, p. 46) stated that "to make a decision means to make a judgment regarding what one ought to do in a certain situation after having deliberated on some alternate course of action." "Decision-making is a deliberative and decisive social action, concerned with choosing what to do in the face of a problem" (Ejimabo, 2015, p. 2). For the purpose of this study, decision-making is defined as "a process that chooses a preferred option or a course of actions from among a set of alternates on the basis of given criteria." The decision-making of business leaders involves series of activities including their courage and evaluation (Ejimabo, 2015), as well as:

[...] gathering, interpreting and exchanging information, creating and identifying alternative courses of action, choosing among alternatives by integrating the often differing perspectives and opinions of team members; and implementing a choice and monitoring its consequences" (Ejimabo, 2015, p. 6).

The next section analyzes the link between leadership and decision-making. 


\subsection{Leadership and decision-making}

Business leaders make decisions on a daily basis, no matter the small or large impact of these decisions on their company. Leaders know the importance of evaluating a situation prior to decision-making. Studies have shown that decision-making of leaders is influenced by several significant factors. These factors include cognitive biases (Stanovich and West, 2008), beliefs (Acevedo and Krueger, 2004), culture (Morgan, 1997), emotions, leadership style, communication and social responsibility (Fischhoff, 1996). The factors that influence the decision-making depend on what decisions are made (Ejimabo, 2015). As decisionmaking is part of the everyday life of leaders in their workplace, apart from the outcomes, is at the heart of the work of management and a key aspect of the organizational outcomes (Barnard, 1968; Donaldson, 1983). The five next sections review the five main dimensions of the decision-making process, namely, mental, emotional, cultural, ethical and spiritual.

\subsection{Mental decision-making}

In today's world, with the broader and larger business community coping with changing dynamics such as the rapid development of technology or the uncertain economic growth linked to the COVID-19 pandemic, business executives who are sitting at the top are well aware of the limitation of conventional decision-making. They make decisions involuntary in a limited time frame, choosing from a variety of alternates that they may have faced for the first time. These alternates may also be exceptional and vague with little information to make a decision. This context is most of the time the one in which business leaders evolve and may not lead to rational decision-making practices. Some leaders might unknowingly respond to the urgency of the situation by changing the usual way of decision-making and, quite often, it means turning to intuition. Intuition is not a new concept, although, until recently, it has been limited to the dominion of philosophy. Recent findings in the field of psychology on how humans process information have spilled over to management research. Though researchers do not agree on what drives intuition, they agree on three possible features of intuition, namely, it is a non-conscious process; it relies on emotional cues; it filters information in a non-sequential manner. According to the cognitive-experiential selftheory, individuals are capable of using rational processes such as logic or analysis and intuition both interchangeably and simultaneously. It means using reasoning on the conscious level and relying on instincts on the non-conscious level (Sinclair and Ashkanasy, 2002). Another dimension of decision-making is emotional and is reviewed in the next section.

\subsection{Emotional decision-making}

Several researchers have identified the influence of emotion on one's decisions but there is limited information about how these emotions influence the decision-making process (Gaudine and Thorne, 2001). Emotion is a reaction that occurs when individuals encounter significant relationships with others or with their environment (p. 175). Frijda (1986) defined emotional phenomena as:

[...] non-instrumental behaviors and non-instrumental features of behavior, physiological changes, and evaluative, subject-related experiences as evoked by external and mental events, and primarily by the significance of such events. An emotion is either an occurrence of phenomena of these kinds or the inner determinant of such phenomena (p. 4).

A contrast has been made between emotions, moods and personality traits, as their boundaries are not well-defined. The distinction between moods and emotions are that moods are of low intensity, enduring and are little specific to the environment. Another 
difference between moods and emotions is the lack of awareness of an individual's cause of the feeling state. The differences of personality traits are that it is less intense, long-lasting and unlinked by the specific environment motives of an individual (Gaudine and Thorne, 2001). There are two dimensions that comprise emotion, namely, one is the level of arousal and the other is the feeling state. The degree of intensity of the feeling state and its level may range from quite to arouse and the later has been defined along two dimensions, namely, negative and positive affect. Negative affect comprises of emotions such as anger, fear, frustration and depression while positive affect consists of emotions such as optimism and joy. Many psychologists now believe that emotions are the dominant driver of the decisionmaking process. Decisions are the channels through which emotions direct our day-to-day efforts to increase positive feelings while avoiding negative feelings. Although the development of the psychological field of emotion science was slow in the beginning, the field of emotion and decision-making is growing at an accelerating rate with the impact of theories in decision-making (Lerner et al., 2015). Another dimension of decision-making is cultural and is reviewed in the next section.

\subsection{Cultural decision-making}

The perspective of decision-making is not so crystal clear, there are several factors that need to be considered such as the range of choices, the outcome of a decision, the identification of well-known patterns and how people narrate the context. These factors are all considered either consciously or unconsciously. The cultural context shapes the impact of these additional factors on decisions made, either if an individual acknowledges the role of culture in the decision-making or not. Such effects jointly influence the sense-making events of people (Glazer and Karpati, 2014). Sense-making is a process in which an individual endeavor to comprehend and interpret experiences. The past experience of an individual, cultural values and the measure, which he gives to the event, all have an impact on what he sees as a situation. Decision-makers also consider what is not stated, and cultural context mostly prescribes the meaning of what is not said. By recognizing what is stated and what is not, one can infer a culture, including an organization's culture. Culture refers to the character of a group of people who share a common history and perception of appropriate normative behaviors, values and beliefs (Glazer and Karpati, 2014). In organizational context and globally, national culture and its values and beliefs are considered. A nation's cultural values represent desired principles that guide individuals' behaviors, feelings and thinking (p. 24). This describes why humans notice artifacts such as organizational processes or experience events like late arrivals to the meetings (as a sign of authority, illmanners or no problem). Similar to values, a culture's social axioms are defined as basic premises that people endorse and use to guide their behavior in daily living (p. 25) gives a basis for understanding the basic thought that directs an individual's behaviors, feelings and interpretations of events (p. 24). Both cultural values and social axioms make the consideration of an individual while information gathering regarding a situation that needs a decision (Glazer and Karpati, 2014). Another dimension of decision-making is ethical and is reviewed in the next section.

\subsection{Ethical decision-making}

Leadership researchers focused on the ethics of the decision-makers found that their decision are governed by the utilitarian, rights and fairness (or justice) perspectives. The utilitarian perspective is mostly used in business decisions aiming on the creation of the highest possible benefit for the organization. Its significant concepts are efficiency, productivity and profitability. For business leaders to achieve their stated targets, the best 
approach that has been suggested is utility maximization. While decision-making, leaders have to avoid injury in a so-called precautionary principle. This perspective stresses on the consideration of the individual basic rights such as the right of free speech. The justice (fairness) perspective: in the available literature, there is a difference distributive justice and procedural justice. The distribution of resources as equitable as possible in full equality (equity) or on need-based is regard to distributive justice. While the process of making justice as fair as possible disregarding the difference outcome for different individuals is assumed as procedural justice (Selart, 2010). Every leader seeks to have influence in a way or another. The essential concern is not whether a leader uses the power or not, the main concern is that how a leader uses the power. Therefore, the interest of many people in ethical leadership and decision-making arises because of the abuse of power in these decisions. Although there is an excessive interest in ethical leadership and decision-making, until now, there is no general agreement on the measurement of this term, it might be because of the absence of a neutral basis for it. There are various criterions for the assessment of leaders, for instance, a leader's influence, intensions, choice selection, behavior, moral development and values. Thus, maintaining and developing professional skills are important for leaders. In a business organizational context, maintaining loyalty to the board as far as possible is significant for a leader (Selart, 2010). The other aspect of ethical leadership decisions is the individual needs and personalities of a leader. If a leader has such personality characteristics such as narcissism, power orientation and lack of emotional maturity (p. 41), it can destroy self-centered behavior rather than others. These leaders seldom trust others and focus on their self needs and career rather on the performance of their organization. Additionally, there is a link between social context and the ethical decision-making of a leader, which is significantly influenced by the situation. Unethical behavior in leadership decision-making can be seen in a business organization that possesses the following characteristics, namely, high productivity demands, internal competition for rewards and advancement, a strong emphasis on obedience and authority and a lack of standards for ethical behavior and individual responsibility (Selart, 2010, p. 41). Another dimension of decision-making is spiritual and is reviewed in the next section.

\subsection{Spiritual decision-making}

Workplace spirituality has been a well-liked topic within the academic community over the past decades. Despite extensive interest within the topic, only a few articles finding the intersection of leadership decision-making and spirituality have explicitly addressed strategic leadership. A line of empirical research in religious research studies examines decision-making styles, for instance, three styles of decision-making processes were represented, namely, deferring, collaborative and self-directing. In the religious context, deferring is that I let God decide for me, the collaborative is that God and I decide together and self-directing is that I decide without the help of God (Van Buren and Agle, 1998, p. 162). In the current literature of spirituality, the role of religion in conceptualizing spirituality seems mostly debated. In his research on business leaders regarding religion's influence on their decision-making, Fernando (2005) found out no universal definition of the concept. The responses from the participants showed that there is a possibility to be spiritual without believing in or affirming to God or higher power, although the majority of the participants explicitly included the belief of higher power as an essential part of their thought of spirituality (Fernando, 2005). When business leaders have been asked about their engagement of religious practices at work, it has often been revealed that involvement is associated with decision-making. The next section will discuss the methodology. 
The purpose of this paper is to understand, which internal processes (mental, emotional, cultural, ethical and spiritual) Afghan business leaders use when making managerial decisions. Primary data were collected through 1-h face-to-face interviews with business executives. Interviews were conducted through open-ended questions in a semi-structured format. This method was considered the most appropriate to acquire an understanding of senior executives' interpretation and usage of decision-making processes. The method of analyzing data was thematic analysis where the researchers identified common themes, topics, ideas and patterns of meaning that come up repetitively. The objective of the analysis was to determine the most used decision-making process by the selected business executives and the reasons for using these processes. The participants were selected on the basis of the following criteria:

- Afghan businessman or CEO based in Kabul.

- Ability to be interviewed in English.

- Having above 24 years of age.

- Having a university degree.

- Working or owing the business for more than a year.

- Willingness to participate in one face-to-face interview.

- Willingness to have their contributions to the study publicly disseminated.

The participants were sourced out by personal business or academic relations and through the selected participants based on their availability and fulfilling the above-mentioned criteria. The group consisted of eight Afghan business leaders that either own the business or are employed as the executive of the company or both owns and serves as an executive of the company. The participants were all born, raised and (mostly) educated in Afghanistan. Their businesses, families and social networks were all located in Afghanistan. All the companies are based in the capital city of Kabul and the respondents work at the Head Office of their respective companies. Out of eight male participants, two were from Generation X (people born from 1965 to 1980) and six from Generation Y or Millennial (people born from 1981 to 1996). Most of the participants are young entrepreneurs that founded their company in the past decade. The next section gathers the results of the interviews.

\section{Results}

The purpose of the paper is to understand which internal processes (mental, emotional, cultural, ethical and spiritual) Afghan business leaders use when making their managerial decisions.

To gather specific data on the research topic, participants explained, which internal processes of decision-making they regularly use in their organization. As shown in Appendix, questions were prepared to minimize participants' replies bias. They were also designed to collect a maximum of information.

The first six questions focused on demographics, education and experience of the participants.

Participants' average of professional experience in years was 11.75 years with a range of 7 years to 25 years. Participants' average number of years working with the current organization (either owing it or working for it) was 6.75 ranging from 3 years to 18 years. The average number of total professional experience for Generation Y (people born from 1981 to 1996) was 8.7 years while their working experience or owing the business was 
3.7 years. The average number of total professional experience for Generation $\mathrm{X}$ was 21 years while their working experience or owing the business was 16 years. Participants of the Generation X (people born from 1965 to 1980) were the founder, owner and executives of the company while in Generation Y, one participant was working as an executive and another participant was only the owner (President) of the company and the remaining four participants were founder, owner and executives of the company.

Table 1 summarizes the participants' age, total years of professional experience and tenure in the current organization.

Questions 7 to 20 were designed to obtain the maximum perception of participants regarding the internal process of decision-making in the context of the study.

Interview question 7: "When we make decisions, there are two types of emotions we mostly feel, namely, incidental and integral. Which one you have experienced more?"

The most frequent type of emotion that the participants used was integral. Out of eight participants, five of them stated that they mostly use integral emotion while making decisions. Two of the participants indicated that they use both integral and incidental emotion in their decision-making. Only one of the participants mentioned that he frequently uses incidental emotion in his decision-making. Some of the participants did not completely understand the meanings of the integral and incidental emotions in the decision-making, to have a harmonized approach, the meaning of both terms were presented to the participants with relevant examples so that all the participants understand the question and provide accurate information. The replies of the participants indicated that all eight participants use the internal process of emotions in their decision-making, but the usage is not frequent. Out of eight participants, only two of them indicated that emotions mostly influence their decision-making process, the remaining participants stated that only on few occasions or sometimes, emotions influence their decision-making. One of the participants stated "I am very rational at decision-making" and the other participant told that "I take time to make decisions." This indicated that they do not allow emotions to have an impact on their decision-making process. One participant of Generation X mostly uses integral emotions and the other participant stated the usage of both incidental and integral emotions in their decision-making. In Generation Y, four out of six participants use integral emotions in their decision-making, one of the participants uses incidental emotions while the other one uses both integral and incidental emotions:

Interview question 8: "How emotions have influenced your decision-making? If you can share any of your experience".

In total, $100 \%$ of the participants indicated that they use emotions while making a decision in their organization, for at least once. The emotional process of decision-making was more involved when the human factor was involved. For instance, one of the participants stated "I

\begin{tabular}{lcccc}
\hline Generation & No. of participants & Average age & $\begin{array}{c}\text { Average years of } \\
\text { work experience }\end{array}$ & $\begin{array}{c}\text { Average time at } \\
\text { current organization }\end{array}$ \\
\hline Generation X & 2 & 44 & 21 & 16 \\
Generation Y & 6 & 31 & 8.7 & 3.7 \\
\hline
\end{tabular}

Table 1

Participants' age, professional experience and tenure in current organization distribution 
did not fire an employee that I had to" because he was a needy and poor person. Most of the participants replied that the usage of emotion in their decision-making depends on the situation. Another participant said that on the closure of some projects, laying out employees feels bad.

The information gathered from the participants showed that due to the negative impact of emotions, more specifically negative emotions, the participants try to avoid the influence of emotions. Like one of the participants said:

I gain negative emotions after business hours, mainly on evenings, so I do not make any decision at that particular time. Because it makes me regret and the impact has been negative most of the time.

The purpose of this question was to determine how emotions impact the decision-making of participants and to identify the occurrence of such impacts. The replies from the participants pointed out that all the participants have incurred emotional processes in their decision-making. It was also observed that some of the participants have tried to avoid the influence of emotions in their decision-making to avoid any unwanted outcome:

Interview question 9: "What different ways of decision-making you prefer to use in your day-to-day work (intuition or logic)?”

The most frequent way of the mental process of decision-making was intuitional decisionmaking. Out of eight participants, four participants replied that they mostly use intuition in their decision-making process. One of the participants replied that his decisions are based on both intuition and logic. The remaining three participants mentioned that they make decisions logically.

The participants were given appropriate examples of both logic and intuition in addition to their definitions, so the participants could share their actual experience. One of the three participants who prefer logical decision-making noted "I like calculations and I consider all the pros and cons of the given alternate before coming to a decision." The other participant who prefers intuition stated "I usually decide the matters based on my vast past experience."

The purpose of this question was to determine the usage of the mental process of decision-making among the participants. The information gathered from the participants showed that mental process is crucial in the decision-making process of the participants and all eight participants indicated that they use this process frequently while making decisions. In addition, all eight participants mentioned that they prefer to use the mental process in their day-to-day decision-making.

Among Generation X, one participant uses the logical process and the other participant mentioned that he uses both logic and intuition in his decision-making process. While among Generation $\mathrm{Y}$, four out of six participants make a decision based on intuition and the remaining two participants use logic for their decision-making:

Interview question 10: “Are you a risk-averse or risk-seeking person with the decision?"

Most of the participants mentioned that they are a risk-seeking person. They revealed that without being a risk-seeking person, working in the business community of Afghanistan would be impossible. They mentioned that the current situation of Afghanistan requires being a risk-seeking person. Out of eight participants, only one participant stated that he is a risk-averse person and the remaining seven participants consider themselves risk-seeking person. All Generation X participants are risk-seeking and only one out of six participants of Generation $\mathrm{Y}$ is a risk-averse person. One of the participants noted, "I am a very risk-seeking 
person, I have invested in many projects and I can even implement a project without having the required financials":

Interview question 11: "What is important for you as a leader to consider when formulating your analysis?”

Due to the openness of the question, the answers provided by the participants varied extensively. While the most common factor mentioned by participants was the outcome and end-result, many other factors were also presented. They included: calculation of alternates, the big picture, relationships, pros and cons of the alternates, success, the end result, values, commodity, justice, human values, ethical values, integrity, feeling responsible, ownership and profitability.

The purpose of this question was to determine, which internal factor(s) participants usually consider in their decision-making. The data gathered from the participants indicated that mental and ethical factors are the most used by participants even if each participant has a unique perspective:

Interview question 12: "Maximizing profit or ethical values, what are your priorities in the organization?"

In total, $100 \%$ of the participants stated that their priorities are more ethical than maximizing profit. The purpose of this question was to determine the usage of the ethical factor in the decision-making of Afghan business leaders (participants).

A participant noted, "when you consider ethics and fulfill your obligations, the profit automatically generates." Another participant stated, "we got projects on the basis of ethical values and there were chances to get extra profit but due to the unethical considerations we did not get those projects."

The data gathered from the participants indicated that all participants are greatly influenced by ethical values in their decision-making process. The participants have the perception that profit is associated with ethical values. They believe that profit will be generated while considering ethical values:

Interview question 13: "What type of organizational culture does your organization possess?"

Out of eight participants, five participants stated that they have an open, friendly, caring organization for each employee and horizontal culture in their organization. The remaining three participants also indicated that they have a friendly culture in their organization but they also consider the processes and hierarchy. The information gathered from the participants showed that most of the participants' organizations had adhocracy or entrepreneurial culture. They valued creativity, participation and flexibility. The purpose of this question was to determine the culture of the organizations, as the literature indicated that leaders tend to dominate the culture in the organizations. Most of the participants also believe that the culture of their organization is the mirror of themselves:

Interview question 14: "How can an organizational culture influence you as a leader? How can you as a leader influence organizational culture?"

The purpose of this question was to know how the culture process of decision-making impacts the decision-making process of its leader. It was found that all the participants use 
the culture process in their decision-making. All participants believe that the influence is on both sides. For instance, one participant noted:

[...] when I joined the organization, it had a too opened and friendly culture while I was a structured and process-based person. Gradually the organization and myself we have influenced each other. Now I am a little more flexible and the organization has adopted processes, it has followed hierarchy but it has preserved its friendly and cooperative culture but not as much as it was.

The information gathered from the participants indicated that the culture process is used in the decision-making process by all participants. In total, $100 \%$ of the participants agreed that they consider culture when evaluating alternate for their decision-making:

Interview question 15: "Have you ever embodied spirituality in your decision-making or will you?"

The answer to this question by all the participants was yes. Every participant agreed that they use spirituality while decision-making. One participant noted, "once in a lifetime I have to consider spirituality in my decision-making." The purpose of this question was to determine whether participants use spirituality in their decision-making process. Considering the socio-cultural virtues of Afghanistan, all participants consider spirituality and religion as the same phenomena. All participants indicated that the teachings and living standards of the families make them believe that both are the same phenomena. A participant said, "yes, I have embodied spirituality in my decision-making because sometimes I have to." While another participant described that his goal in the organization is spiritual, he also mentioned that this inspired him to write on the effects of spirituality on work-life, a chapter in his upcoming book. Another participant said that the usage of spirituality in decision-making relates to being ethical. The information gathered from participants on this topic clearly indicates that they use spirituality in their decision-making:

Interview question 16: "How much you rely on spirituality while decision-making?"

Out of eight participants, three participants replied that they mostly rely on spirituality or on their religious teachings during the decision-making process. Another three participants replied that they somehow rely on spirituality or religion in their decision-making, about $50 \%$ of the time. The remaining two participants indicated that they rely on spirituality in their decision-making between $25 \%$ and $30 \%$ of the time. They expressed that most of the decision-making in their line of work does not require spirituality to be involved. They consider other processes to make decisions. The information gathered from the participants exhibited that participants from Generation Y rely $76 \%$ on spirituality in their decisionmaking process. The data showed that only one of the Generation Y participants rely less on spirituality and the remaining five participants rely frequently on spirituality while making a decision. The information from Generation X indicated that these participants rely less on spirituality, their average was 38\%. One of the Generation X participants stated "I rely less, as I do my work based on my evaluations":

Interview question 17: "How do the spiritual beliefs affect your decision-making?"

All participants acknowledged that spiritual belief has affected their decision-making process. Most of the participants recognized that the affects come from their religious beliefs and daily prayers. The factors that affect the decisions of the participants vary, they include stress, ethical values, national culture, destiny, religious beliefs, family background, 
satisfaction and religious teachings. A participant noted that "after all considerations and analysis, I make a decision then I leave it to God." Three participants admitted that spirituality gives them relief from stress, one of them also mentioned that it gives him satisfaction when he relies on spiritual decision-making. Two participants replied that the influence of religion on their decision-making comes from religious family background. They mentioned that the teachings they had throughout their life have stimulated their consideration of religion in their decision-making. The purpose of this question was to better understand the impact and usage of spirituality in the daily decision-making process of the interviewed participants. One participant noted, "at certain times, I made bad decisions, and these bad decisions pushed me to use spirituality in my decision-making process."

The information gathered in the research clearly advocates that the spirituality of participants relies on their religious beliefs. These beliefs come from the teachings and national culture that participants received and practice every day:

Interview question 18: "Decision-making is a choice from among two or more alternate courses of action, what process kicks first inside you when making a decision?"

Out of eight participants, six mentioned mental process, one participant emotional process and one cultural process. Five participants explicitly stated that they seek the end-result or outcome of the alternates. The process that "kicks first inside the leader" varies from participants: outcome of the decision, result, process, solution time, logical evaluations, motivation, passion, questions in mind, impact and reaction of the people. The purpose of this question was to determine the first reaction of the participants in their decision-making. Although each internal process was determined individually from the information provided by the participants, the objective was also to compare the processes within the decisionmaking of the participants. A participant noted, "I am rational in my decision-making, I do not make quick decisions, I first calculate, evaluate before coming to a final decision":

Interview question 19: "What attitude you adopt when facing an organizational problem? (Offensive or defensive)?"

Five participants out of eight replied that they have mostly adopted a defensive attitude. The remaining three participants have adopted offensive attitude when facing an organizational problem. These three participants belong to Generation Y, hence, three participants from Generation Y and both participants from Generation X adopted a defensive attitude. To better understand the terms offensive and defensive decision-making, both terms were defined in accordance to the decision-making process with associated examples. One participant that has adopted a defensive attitude noted "once I have made a decision without considering and evaluating the problem, I regret when I come to know the real reason behind the problem." The purpose of this question was to determine the usage of mental processes in decision-making and to understand the overall attitude of participants when they make decisions in their organizations:

Interview question 20: "How the COVID-virus pandemic has impacted your decisionmaking process? Which dimension has been impacted? Mental, emotional or spiritual?"

All participants acknowledged that the current COVID19 pandemic has impacted their businesses and their decision-making process as well. The information gathered from the participants revealed that the COVID19 pandemic has impacted six participants from out of 
eight in their mental decision-making process, and the remaining two participants mentioned that the pandemic has had a significant impact on their emotional process of decision-making. One of the participants of Generation X has had an emotional impact on his decision-making process and the other participant of Generation X has had a mental impact. Considering Generation Y, five out of six participants have had a mental impact on their decision-making process and the remaining one has had an emotional impact. Most of the participants replied that the pandemic had more impact during the downsizing of their organization due to financial losses and another impact was the task delays. The purpose of this question was to analyze the effects of the COVID19 pandemic.

In conclusion, the answers to interviews reveal that all the internal processes are used by participants in their decision-making but their utilization varies with individuals: the most frequent processes in decision-making are mental, cultural and ethical processes. Both Generations X and Y used more mental, cultural and ethical processes in their decisionmaking. Table 2 indicates the usage of the mental, emotional, cultural, ethical and spiritual process in decision-making and its distribution.

\section{Conclusion}

The primary source of data collection was a sample of eight Afghan business leaders who either work as an executive or own the company or both in Kabul city, capital of Afghanistan. The data was collected from open-ended, semi-structured, face-to-face interviews conducted with each participant. The objective of this study was to explore the most frequent factors (mental, emotional, cultural, ethical and spiritual), which influence the decision-making processes and to better understand the psychological process of decisionmaking among business leaders in Afghanistan.

Based on the thematic analysis of the interviews, during the mental process of decisionmaking among participants, the most frequent way is intuitional decision-making. Out of eight participants, four participants replied that they have mostly used intuition in their decision-making process. One of the participants replied that his decisions are commonly based on both intuition and logic. The remaining three participants mentioned that they make decisions logically. These findings indicate that the mental process is involved in the decision-making process of all participants. Klein and Weick (2000) explained that decisionmaking involves essentially three approaches, namely, the rational choice, the intuitive and the experimental approach. Decision-making improves with practice as it is considered as a skill. One of the participants stated, "I am very rational at decision-making" in agreement with Faules and Alexander (1978), who noted: "during most of this century logical thought has been regarded as the basis for decision-making” (p. 178). Among Generation X, one participant uses the logical process and the other participant uses both logic and intuition in his decision-making process. According to the cognitive-experiential self-theory individuals

Table 2 .

usage distribution of the mental, emotional, cultural, ethical and spiritual process in decisionmaking

\begin{tabular}{|c|c|c|c|c|c|}
\hline Generation & $\begin{array}{l}\text { Usage of } \\
\text { mental process }\end{array}$ & $\begin{array}{l}\text { Usage of } \\
\text { emotional process }\end{array}$ & $\begin{array}{l}\text { Usage of } \\
\text { cultural process }\end{array}$ & $\begin{array}{l}\text { Usage of } \\
\text { ethical process }\end{array}$ & $\begin{array}{l}\text { Usage of } \\
\text { spiritual process }\end{array}$ \\
\hline Generation Y & $\begin{array}{l}\text { Mostly } \\
(75 \% \text { to } 100 \%)\end{array}$ & $\begin{array}{l}\text { Often } \\
(50 \% \text { to } 75 \%)\end{array}$ & $\begin{array}{l}\text { Mostly } \\
\text { (75\% to } 100 \% \text { ) }\end{array}$ & $\begin{array}{l}\text { Mostly } \\
(75 \% \text { to } 100 \%)\end{array}$ & $\begin{array}{l}\text { Mostly } \\
(75 \% \text { to } 100 \%)\end{array}$ \\
\hline Generation X & $\begin{array}{l}\text { Mostly } \\
\text { (75\% to } 100 \% \text { ) }\end{array}$ & $\begin{array}{l}\text { Sometimes } \\
\text { (less than 50\%) }\end{array}$ & $\begin{array}{l}\text { Mostly } \\
\text { (75\% to } 100 \% \text { ) }\end{array}$ & $\begin{array}{l}\text { Mostly } \\
\text { (75\% to } 100 \% \text { ) }\end{array}$ & $\begin{array}{l}\text { Sometimes } \\
\text { (less than } 50 \% \text { ) }\end{array}$ \\
\hline All & $\begin{array}{l}\text { Mostly } \\
\text { (75\% to } 100 \% \text { ) }\end{array}$ & $\begin{array}{l}\text { Often } \\
\text { (50\% to } 75 \%)\end{array}$ & $\begin{array}{l}\text { Mostly } \\
\text { (75\% to } 100 \% \text { ) }\end{array}$ & $\begin{array}{l}\text { Mostly } \\
\text { (75\% to } 100 \% \text { ) }\end{array}$ & $\begin{array}{l}\text { Often } \\
(50 \% \text { to } 75 \%)\end{array}$ \\
\hline
\end{tabular}


are remarkably capable of using rational processes such as logic or analysis and intuition both interchangeably and simultaneously. It means that the individual uses reasoning on the conscious level and relies on instincts on the non-conscious level (Sinclair and Ashkanasy, 2002). Among Generation Y, four out of six participants make a decision based on intuition and the remaining two participants use logic for their decision-making.

Regarding the emotional process of decision-making, all participants indicate that they use emotions while making a decision in their organizations, at least once. The emotional process of decision-making is more involved when the human factor is involved. For instance, one of the participants stated "I did not fire an employee that I had to because he was a needy and poor person." This statement is in line with Gaudine and Thorne (2001, p. 175): "emotion is a reaction that occurs when individuals encounter significant relationships with others or with their environment." Thus, all eight participants have used the internal process of emotion in their decision-making, but the usage has not been frequent. Out of eight participants, only two indicated that emotions have most influenced their decision-making process, the remaining six stated that only in few occasions or sometimes the emotions have influenced their decision-making. One of the participants stated, "I am very rational at decision-making and do not allow emotions to interfere on my decisions." In this respect, Kim (2012) explained that "emotions interfere on rationality, affecting one's objective observation of the situation, as there is a complementary relationship between both, as an emotion has an important role in the decision-making process."

Regarding the cultural process of decision-making, Glazer and Karpati (2014) mentioned that decision-makers consider what is not stated, and cultural context mostly prescribes the meaning of what is not said. By recognizing what is stated and what is not, we can infer a culture, including an organization's culture. In line with this statement, participants were asked about their organizational culture to determine their usage of cultural processes in decision-making. Out of eight participants, five participants stated that they have an open, friendly, caring organization for each employee and horizontal culture in their organization. The remaining three participants indicated that they have a friendly culture but they also considered the processes and hierarchy in their organization. The information gathered from the participants showed that most of the participants' organizations had adhocracy or entrepreneurial culture. They valued the creativity, participation and flexibility of employees. Leaders of this type of organization were mentioned by Chatman and Kennedy (2010) indicating that all employees will either succeed or fail together when employees share the organizational culture values of a group, and therefore, share its fate.

Regarding the ethical process of decision-making, all participants stated that their priorities are more ethical than getting extra profit. The data indicated that all participants have been influenced by ethical values in their decision-making process. The participants have the perception that profit is associated with ethical values. They believe that profit will be generated while considering ethical values. A participant noted that when you consider ethics and fulfill your obligations, the profit automatically generates. Thus, researchers argued that leadership is considered to be effective and true when the behavior and role of the leader are consistent with ethical and moral values (Kooskora, 2012). There are various criterions for the assessment of leaders, for instance, a leader's influence, intentions, choice selection, behavior, moral development and values (Selart, 2010). The results of this study support this finding, for instance, a participant stated "we got projects on the basis of ethical values and there were chances to get extra profit but due to the unethical considerations we did not get those projects." 
Regarding the spiritual process of decision-making, out of eight participants, three participants replied that they mostly rely on spirituality or on religious teachings during the decision-making process. Another three participants replied that they somehow rely on spirituality or religion in their decision-making, about $50 \%$ of the time. The remaining two participants indicated that they rely on spirituality in their decision-making between $25 \%$ and $30 \%$ of the time. All participants agreed that they have used spirituality while decisionmaking. One participant noted that once in a lifetime he has to consider spirituality in his decision-making. A line of empirical research in religious research studies examined decision-making styles. Among these styles, three styles of decision-making processes stand out: deferring, collaborative and self-directing. In the religious context, deferring is "I let God decide for me," collaborative is "God and I decide together" and self-directing is "I decide without the help of God" (Van Buren and Agle, 1998, p. 162). In line with this statement, a participant noted "after all considerations and analysis, I make a decision then I leave it to God." One participant noted, "at certain times, I made bad decisions, and these bad decisions pushed me to use spirituality in my decision-making process".

This finding is supported by Fernando (2005), who mentioned that some leaders believe that in difficult situations their connectivity with religion needs to be complemented with the available decision-making tools, as the need to make the right decision is the main concern.

In conclusion, this paper discusses the decision-making process of business leaders and focuses on which internal factors do Afghan business leaders select when making a decision. The main factors encountered in the literature are mental, emotional, cultural, ethical and spiritual. Although the usage of internal processes in decision-making are not homogeneous among Afghan business leaders, some of the processes are used more frequently than others such as mental, cultural and ethical processes. During the mental process of decision-making, the majority of leaders use intuitional decision-making, the minority using logic. Regarding the cultural dimension, the majority of leaders stated that they have an open, friendly, caring organization for each employee and horizontal culture in their organization. The minority indicated that they have a friendly culture but they also considered the processes and hierarchy in their organization. Considering the ethical process of decision-making, leaders stated that their priorities are more ethical than getting extra profit. They believe that profit will be generated while considering ethical values. As a leader noted: when you consider ethics and fulfill your obligations, the profit automatically generates. Most leaders use the internal process of emotion in their decision-making, but the usage has not been frequent. The emotional process of decision-making is more involved when the human factor is involved. For instance, one of the participants stated "I did not fire an employee that I had to because he was a needy and poor person." About the spiritual process of decision-making, although all leaders agreed that they have used spirituality in decision-making, its usage varies. About one-third of the leaders mostly rely on spirituality or on religious teachings during the decision-making process, one third somehow rely on spirituality or religion, about $50 \%$ of the time and one third rely on spirituality between $25 \%$ and $30 \%$ of the time. This study is pilot research as no previous research was carried out on this topic, therefore it provides a basis of literature on the usage of internal processes on decision-making in Afghanistan. Additionally, it offers insight for international business leaders who are eager to deal with Afghan business leaders. To have a better knowledge of the usage of internal processes in decision-making in Afghanistan, future research studies may broaden the number of participants, include both genders and include more business sectors and industries, as this study has limitations. The most significant limitation of the study is the usage of a small sample size. Interviews being face-to-face for the quality of 
the interaction with leaders, it was a serious constraint and because of security reasons, the capital and the country being the regular targets of terrorist attacks that limit travel, the sample size was limited. Another limitation is the unavailability of academic literature on internal processes of decision-making in Afghanistan, no previous research having been conducted on this topic. In addition, Afghanistan having socio-cultural barriers, the number of female leaders being limited. No female leaders have been interviewed for the purpose of this research.

\section{References}

Acevedo, M. and Krueger, J. (2004), "Two egocentric sources of the decision to vote", Political Psychology, Vol. 25 No. 1, pp. 115-134.

Barnard, C.I. (1968), The Functions of Executive, Harvard University Press, Cambridge, MA.

Case, L. (2010), “Great leaders are great decision-makers”, Graziadio Business Review, Vol. 13 No. 4, pp. 1-7.

Chatman, J.A. and Kennedy, J.A. (2010), "Psychological perspectives on leadership", In The Theory of Leadership, Harvard Business Press, Boston, MA, pp. 1-23.

Donaldson, G. (1983), Decision Making at the Top: The Shaping of Strategic Direction, Basic Books, New York, NY.

Ejimabo, N.O. (2015), "The influence of decision making in organizational leadership and management activities", Journal of Entrepreneurship and Organization Management, Vol. 4 No. 2, pp. 1-13.

Faules, D.F. and Alexander, D.C. (1978), Communication and Social Behavior: A Symbolic Interaction Perspective, Addison-Wesley Publishing, Reading, MA.

Fernando, M. (2005), “Religion's influence on decision-making: evidence of influence on the judgment, emotional and motivational qualities of Sri Lankan leaders' decision-making", 21st European Group of Organization Studies (EGOS) Colloquium, pp. 1-17.

Fischhoff, B. (1996), “The real world: what good is it?", Organizational Behavior and Human Decision Processes, Vol. 65 No. 3, pp. 232-248.

Frijda, N.H. (1986), The Emotions, Cambridge University Press, Amsterdam.

Gaudine, A. and Thorne, L. (2001), "Emotion and ethical decision-making in organizations", Journal of Business Ethics, Vol. 31 No. 2, pp. 175-187.

Glazer, S. and Karpati, T. (2014), "The role of culture in decision making”, Cutter It Journal, Vol. 27 No. 9, pp. 23-29.

Harrison, E.F. (1996), "A process perspective on strategic decision making”, Management Decision, Vol. 34 No. 1, pp. 46-53.

Kepner, C.H. (1997), "The new rational manager: an updated edition for a new world", in Kepner, C.H. and Tregoe, B. (Eds), The New Rational Manager: An Updated Edition for a New World, Princeton Research Press, Princeton, NJ.

Kim, K.H. (2012), "Emotion and strategic decision-making behavior: developing a theoretical model", International Journal of Business and Social Science, Vol. 3 No. 1, pp. 105-113.

Klein, G. and Weick, K.E. (2000), “Decisions”, Across the Board, Vol. 37 No. 6, pp. 16-22.

Kooskora, M. (2012), "Ethical leadership, the role of the leader", in Pucetaite, R. (Ed.), Cases in Organizational Ethics, Nordic Baltic ethics series, Vol. 2, pp. 23-39.

Lerner, J.S., Li, Y., Valdesolo, P. and Kassam, K. (2015), "Emotion and decision making”, Annual Review of Psychology, Vol. 66 No. 1, pp. 799-823.

Morgan, G. (1997), Images of Organization, Sage, Thousand Oaks, CA. 
Selart, M. (2010), “A leadership perspective of decision making”, In M. Selart, a Leadership Perspective of Decision Making, Cappelen Damm, AS.

Simon, H.A. (1960), The New Science of Management Decision, Harper, New York, NY.

Sinclair, M. and Ashkanasy, N.M. (2002), "Intuitive decision-making amongst leaders: more than just shooting from the hip", Mt Eliza Business Review, Vol. 5 No. 2, pp. 32-40.

Stanovich, K.E. and West, R.F. (2008), "On the relative independence of thinking biases and cognitive ability", Journal of Personality and Social Psychology, Vol. 94 No. 4, pp. 672-695.

Van Buren, H.J. and Agle, B.R. (1998), "Measuring Christian beliefs that affect managerial decision making: a beginning", International Journal of Value-Based Management, Vol. 11 No. 2, pp. 159-177.

\section{Further reading}

Al Jenaibi, B. (2010), "Differences between gender treatments in the workforce", Cross-Cultural Communication, Vol. 6 No. 2, pp. 63-74.

Al Lamky, A. (2006), "Feminizing leadership in Arab societies: the perspective of Omani female leaders", Women in Management Review, Vol. 22 No. 1, pp. 49-67.

Arsham, H. (2010), "Leadership decision making”, Retrieved February, Vol. 23, 2012.

Blanche, M., Durrheim, K. and Painter, D. (2007), Research in Practice: Applied Methods for the Social Sciences, 3rd ed., Paarl Print, Cape Town.

Bristol-Rhys, J. (2010), Emirati Women, Columbia University Press, New York, NY.

Byres, P. and Wilcox, J. (1991), "Focus groups: a qualitative opportunity for researchers", Journal of Business Communication, Vol. 28 No. 1, pp. 63-78.

Cachia, M. and Millward, L. (2011), "The telephone medium and semi-structured interviews: a complementary fit", Qualitative Research in Organizations and Management: An International Journal, Vol. 6 No. 3, pp. 265-277.

Charmaz, K. (1994), "Discovering chronic illness: using grounded theory”, in Glaser, B. (Ed.), More Grounded Theory Methodology: A Reader, Sociology Press, Mill Valley, CA.

Festinger, L. (1964), Conflict, Decision, and Dissonance, Stanford University Press, Stanford, CA.

Fontana, A. and Frey, J. (2005), "The interview: from neutral stance to political movement", in Denzin, N. and Lincoln, Y. (Eds). The Sage Handbook of Qualitative Research, 3rd ed., Sage, Thousand Oaks, CA, pp. 695-727.

Fritzsche, D.J. (1991), "A model of decision-making incorporating ethical values", Journal of Business Ethics, Vol. 10 No. 11, pp. 841-852.

Garvin, D.A. and Roberto, M.A. (2001), “What you don’t know about making decisions”, Harvard Business Review, Vol. 79 No. 8, pp. 108-116.

Gillham, B. (2000), The Research Interview, Continuum, London, England.

Gordon, R. (1996), "Impact of ingratiation on judgments and evaluations: a meta-analytic investigation”, Journal of Personality and Social Psychology, Vol. 71 No. 1, pp. 54-70.

Krueger, R. and Casey, M.A. (2009), Focus Groups: A Practical Guide for Applied Research, Sage, London, England.

Langley, A., Mintzberg, H., Pitcher, P., Posad, E. and Saint-Macary, J. (1995), "Opening up decision making: the view from the black stool”, Organization Science, Vol. 6 No. 3, pp. 260-279.

Lincoln, Y.S. and Guba, A.E. (1985), Naturalistic Inquiry, Sage, Beverly Hills, CA.

Litherland, N. (2017), "Decision-making process of managers", bizfluent, available at: https://bizfluent. com/how-does-5280248-decisionmaking-process-managers.html (accessed 17 June 2020).

Marshall, M. (1996), “Sampling for qualitative research”, Family Practice, Vol. 13 No. 6, pp. 522-525. 
Miles, M.B. and Huberman, A.M. (1994), Qualitative Data Analysis: An Expanded Sourcebook, Sage, Beverly Hills, CA.

Negulescu, O.H. (2014), "Using a decision-making process model in strategic management", Review of General Management, Vol. 19 No. 1, pp. 111-123.

O’Neill, K. (2011), “Communication channels utilized by Emirati females to enact leadership”, Doctoral dissertation, available from OhioLINK ETD Center. (antioch1322493547).

Onwuegbuzie, A. and Leech, N. (2006), "Linking research questions to mixed methods data analysis procedures", The Qualitative Report, Vol. 11 No. 3, pp. 474-498.

Phipps, K.A. (2011), "Spirituality and strategic leadership: the influence of spiritual beliefs on strategic decision making", Journal of Business Ethics, Vol. 10 No. 6, pp. 177-189.

Schnurr, S. (2009), Leadership Discourse at Work: Interactions of Humor, Gender and Workplace Culture, Palgrave Macmillian, New York, NY.

Siddiqi, L.A., Chick, H. and Dibben, M. (2017), "Spirituality and its role in responsible leadership and decision-making”, Responsible Leadership and Ethical Decision-Making, pp. 63-81.

Stokes, D. and Bergin, R. (2006), “Methodology or methodolatry'? An evaluation of focus groups and depth interviews", Qualitative Market Research: An International Journal, Vol. 9 No. 1, pp. 26-37.

Thompson, L.L. (2008), Making the Team: A Guide for Managers, 3rd ed., Prentice Hall, NJ.

Tremblay, M. (1957), "The key informant technique: a non-ethnographic application”, American Anthropologist, Vol. 59 No. 4, pp. 688-701.

Tsai, Y. (2011), "Relationship between organizational culture", BMC Health Services Research, BMC Health Services Research, Vol. 11 No. 1, p. 98.

Vroom, V.H. and Jago, A.G. (1974), "Decision making as a social process", Decision Sciences, Vol. 5 No. 4, pp. 743-755.

Wang, Y., R., G. (2007), “The cognitive process of decision making”, International Journal of Cognitive Informatics and Natural Intelligence, Vol. 1 No. 2, pp. 73-85.

Wang, Y., Wang, Y., Patel, S. and Patel, D. (2006), “A layered reference model of the brain (LRMB)”, IEEE Transactions on Systems, Man, and Cybernetics, Part C, Vol. 36 No. 2, pp. 124-133.

Wimpenny, P. and Gass, J. (2000), "Interviewing in phenomenology and grounded theory: is there a difference?", Journal of Advanced Nursing, Vol. 31 No. 6, pp. 1485-1492.

Woiceshyn, J. (2011), “A model for ethical decision making in business: reasoning, intuition, and rational moral principles", Journal of Business Ethics, Vol. 104 No. 3, pp. 311-323.

\section{Appendix. Interview questions}

- What is your job title?

- How long have you been working in this organization?

- What is your highest level of education? And in which institution?

- When did you graduate (from your highest level of education)?

- What are the total years of your professional experience?

- How many places have you worked in?

- When we make decisions, there are two types of emotions we mostly feel, namely, incidental and integral. Which one you have experienced more?

- How emotions have influenced your decision-making? If you can share any of your experience.

- What different ways of decision-making you prefer to use in your day-to-day work (intuition or logic)? 
- Are you a risk-averse or risk-seeking person with the decision?

- What is important for you as a leader to consider when formulating your analysis?

- Maximizing profit or ethical values, what are your priorities in the organization?

- What type of organizational culture does your organization possess?

- How can an organizational culture influence you as a leader? How can you as a leader influence an organizational culture?

- Have you ever embodied spirituality in your decision-making or will you?

- How much you rely on spirituality while decision-making?

- How do the spiritual beliefs affect your decision-making?

- Decision-making is a choice from among two or more alternate courses of action, what process kicks first inside you, when making a decision?

- What attitude you adopt when facing an organizational problem? (Offensive or defensive).

- How the COVID-virus pandemic has impacted your decision-making process? Which dimension has been impacted? Mental, emotional or spiritual?

- Is there anything we did not talk about today that you think we should? Are there any questions that you want us to go back and revisit?

\section{Corresponding author}

Pierre Rostan can be contacted at: rostan.pierre@gmail.com

For instructions on how to order reprints of this article, please visit our website: 